\title{
Examining current research on local food: a review
}

\author{
Marc Hébert \\ This study was conducted under the supervision of Prof. Towhidul Islam \\ Department of Marketing and Consumer Studies, College of Management and Economics \\ University of Guelph
}

\begin{abstract}
The decision to purchase local food is fast growing into a popular movement across North America. This research paper reviews the literature that examined the various consumer behaviour factors surrounding the local food movement, as well as the suggested possible benefits. This research also provides insights gained from in-depth interviews with local food community members to understand the unique characteristics of the local food movement within the author's own community. Finally, suggestions for further research are laid out, indicating considerations required for the replication of studies completed across the United States and London, England.
\end{abstract}

$\mathrm{T}$ The decision to purchase locally is a divisive issue. It has been praised as an opportunity to support the local economy and cut down on the rising costs (fiscal and environmental) of obtaining food from great distances. However, critics regard the movement as a gross oversimplification of food provisioning issues, indicating that transportation is only a small part of the process and "going local" overlooks the rest of the life cycle of food products, such as production and disposal. As a result, there is considerable uncertainty surrounding the "true" benefits of buying local and further research into this area is necessary.

Studies in the past have suggested that consumers are more and more viewing purchasing locally as an appealing option, but are hindered by a lack of awareness and knowledge. Additional research is recommended to better understand consumers' willingness-to-pay for local and sustainable options, thus assessing their tolerance for the possibility of increased prices depending on the producer and quality of growing season for each year. This review explores the current literature on the subject, and also attempts to understand the particularities of the Southern Ontario Local Food Movement by conducting interviews with members of government, agriculture, non-government organizations, and academia.

\section{METHODOLOGY}

In order to determine the various factors involved in the local food movement, a literature review was conducted to examine current studies on consumer behaviour related to local food across North America and Eastern Europe. These studies were selected for their examination of purchase motivations and perceptions of "local". This review was to identify trends in perceptions of local food products, as well as areas where no clear patterns emerged and further study was required.

Additionally, we spoke with members of the local food community to identify current behaviour particular to Southwestern Ontario. These discussions were based upon the supplement entitled "Local Food Products Discussion Guide" contained with this paper. It is important to note that there is a limitation to the use of this material: these interviews and the information given are intended as a basis to develop further research on the region's local food movement, and not as an exhaustive review.

\section{LITERATURE REVIEW}

\section{Consumer Motivations}

For our research, we seek to explore consumer perspectives of local food purchasing. We define "local food" as products produced in Ontario, and purchased from farmer's markets [1], direct farm purchasing [2], and community supported agriculture (CSA) programs [3]. There has been a limited, but detailed, body of work surrounding the consumer factors involved in the local food movement. Primarily this research has focused on consumer motivations for purchasing local. One surprising factor is that income levels and the price of the products are considered as insignificant variables [4], suggesting that this is more rooted in social factors than economic [5]. Furthermore, some suggest that consumers are willing to pay more for local, depending on their support for local economic systems [6] and support for smaller farm operations [7]. Another suggestion is that the products obtained locally have a 
significantly higher perceived degree of freshness and quality [4], which is a very desirable trait for consumers [7,8]. Finally, a major factor impacting consumer purchasing patterns for local food products is the convenience in buying these products [9]. Consumers do have a stated interest in purchasing locally, but require that these purchases fit in with their current grocery buying patterns[2]. Additionally, there is a lack of awareness of the availablity of local food products among consumers [10,11]. This has acted as an impediment to the local food sector and it has been noted that a strong consumer-focused marketing push is needed to place these food products in the hands of these consumers [1,12]. Even in an area where availability is very high, such programs would be beneficial to support the local economy.

\section{Consumer Interpretations of "Local"}

One important factor to note is that the definition of "local" is currently limited to one's own interpretation, as there is no national certification body in place to determine what is unequivocally "local" $[6,7,13]$. Thus, much of the research has sought to determine what the consumer definition of these products is. It has been suggested that social and legal boundaries of state lines [7] play a much more important role than actual geographical distance. In fact, the distance food travels was indicated to be of little importance to some consumers [13]. In other words, consumers would consider "in-state" or "from Ontario" to be equivalent to "grown nearby" or "within 100 miles". Therefore, a certification and labelling initiative would serve some value in promoting local products, similar to the increase in labelling for organic foods that has increased in popularity recently $[6,14]$.

\section{Perceived Advantages}

As previously stated, the true sustainable value of local purchasing is currently undetermined. This is likely a factor that has undermined any initiatives to create a certification body for local food products. However, consumers perceive buying local as having a number of sustainable benefits, and may derive utility from their purchase patterns in the same way that they do from purchasing organic, fair-trade, or other sustainable food products. A major benefit indicated is the belief in supporting the local economy, and directing money towards farmers and smaller producers over larger businesses [15]. This is often cited as "cutting out the middle-man", and is believed to be fairer to producers than other methods of purchasing [16]. Another perceived benefit consumers have indicated is related to sustainability - the belief that food produced locally and without long shipping times has a lower carbon footprint than products shipped from across the world $[1,9]$. Finally, in objection to conventional high-density agricultural operations such as "factory farms" and concentrated animal feeding operations, consumers may purchase locally to support smaller farms that have a perceived higher ethical and environmental standard. This is due in part to growing consumer distaste for antibiotic and pesticide usage, as well as the treatment of farm workers in such operations [16]. While it remains to be seen whether purchasing locally has a better environmental footprint than conventional agriculture, consumers still have strong perceptions and opinions regarding these issues.

It is important to note that the local food movement has the potential to differ greatly based on a number of geographical factors. For example, food that is produced in some locations can be grown throughout the year and uses far different inputs than food produced in Southern Ontario. Therefore, the supporters of local food in Guelph may have different perspectives and motivation than those based elsewhere where research we reviewed was conducted. We felt it was important to assess how much of a difference existed, and how local food initiatives currently exist in our own area of Southern Ontario. Thus, to attempt to "localize" our research, we sought to obtain further insight from indepth interviews with members of the community that are connected to local food issues.

\section{IN DEPTH INTERVIEWS}

We discussed the local food movement with four members of the local food community. They included a Professor at the University of Guelph Department of Food, Agriculture and Rural Affairs with research specializing in food systems; an Officer at the Ontario Ministry of Agriculture, Farms, and Rural Affairs who develops informational programs for Foodland Ontario; a Project Manager at Hamilton Eat Local; and the owner and operator of Heartwood Farms, a Community Supported Agriculture (CSA) program in Guelph.

\section{Definition of "Local"}

On the subject of what constitutes locality, similar to the findings in the literature review, it was unanimous that the local food movement is based on subjective concepts over measurable factors. A strong preference was indicated for products sourced within-province, even if interprovincial purchasing would result in less distance from producer to purchaser. This was specifically noted in the case of institutional buyers, who often source from across the province. Some suggestion was made that the term "local" should only refer to those produced in the same region (eg Wellington County for Guelph), but it was indicated that this may prove to be difficult, particularly in times of regional growing issues or in the off-season when less food is produced.

The two primary sources for local food were indicated to be farmer's markets and community supported agriculture (CSA) programs. These were preferred for their direct connection to farmers and function as a community meeting place (in the case of farmer's markets). Additionally, farm stands were mentioned as another source for local food products, but are not the most preferred due to the inconvenience and potential for long travel times required. 
Finally, it was indicated that grocery stores such as Sobey's and wholesalers such as Costco were beginning to work at stocking local food products, and this was suggested as a potentially large area for growth for the local food sector.

\section{Consumer Motivations}

The factors which motivated consumers to choose local products over non-local were consistent throughout the interviews. Primarily, the major reason was a perceived environmental benefit, particularly in contrast to current fossil-fuel intensive mainstream agricultural processes. Secondly, support for farmers and the local economy were indicated as major reasons why consumers chose local. It was indicated that purchasing locally provided support and fairer conditions to farmers. It also provided consumers with a way of reconnecting with their food, especially through developing personal relationships with the farmers producing it. Finally, freshness and perceived higher quality were noted as a major reason compelling consumers to seek local products. This was also a reason for the high appeal of farmers markets, and indicates the possibility of strong consumer loyalty to producers to continue obtaining products of such high perceived quality.

That said, consumers are occasionally deterred from purchasing locally for a variety of reasons. Convenience is a major issue, as it is crucial to have food purchasing fit with modern lifestyles. Without the freedom of obtaining food products whenever and wherever they would like to, consumers may default to a supermarket chain and what products are provided, regardless of the previously noted factors. Price was also a perceived concern, as it is a common belief that these products do not benefit from the decreased marginal costs that come with high volume. In addition, awareness of where to buy local is low, thus decreasing the likelihood one would seek out local food products. Similarly, there are unique products throughout the seasons and locations that consumers may be unfamiliar with (such as garlic scapes or kale), and this was indicated as a possible deterrence in order for consumers to maintain the status quo at their household.

\section{Benefits of Local}

From the perspective of the interview subjects, the benefits of purchasing locally are mixed. It was noted as being good for the local economy and fairer to farmers. That said, the environmental impacts noted by consumers as incentives were questionable, as there has not yet been any conclusive data that local food purchasing is any better than conventional food purchasing. One interview subject indicated that foods should be evaluated on an individual basis, rather than using an overall measure such as food miles to evaluate the products. Techniques such as life-cycle analysis will provide support in the coming years to better understand the net impact of different food production methods.

\section{Current and Future Support for the Local Food Movement}

To support the local food movement, there are a number of programs currently running. Counties and Regions are currently producing "local food maps", used to build awareness of local farms and markets to purchase at. There are also culinary tourism programs in place to visit producers across the province to see what is available in Ontario and better understand how it is produced. The provincial government is also supporting by using "Foodland Ontario" labels and marketing programs to ensure customers are aware of Ontario products. This also includes cooking and seasonality information to help consumers build Ontariogrown food into their regular consumption patterns. At the producer level, there are education programs in place to build an understanding of how best to market and provide food products. This has helped to develop farmer entrepreneurship and increase availability of local food products. The groups that the interviewers believed to be the best target for the consumer programs were average income families across all demographics, as the products are not overly expensive or difficult to obtain. Particularly, lower to middle income groups were noted as high-priority groups, as they are also the target of nutrition initiatives that tie in with the "fresh and healthy" motifs of local food movement promotional campaigns.

It was indicated that further support should be available to develop the local food movement. A particular initiative noted was the development of a local food section at major grocery stores, similar to the recent introduction of organic product sections. Further education to develop farmer's business knowledge was also indicated as extremely necessary. The overall themes persisting throughout the interviews were that customers should be made more aware of the availablity of local food products and that farmers should be helped in developing sustainable operations. Subsidies were indicated as an unhelpful method of support, as they tended to distort markets. By developing the programs available now and creating additional initiatives, the local food sector will be able to develop further and be better understood as a major part of Ontario's economy.

\section{FURTHER RESEARCH}

This review of the current research suggests that consumers derive a high degree of utility from the intangible benefits of purchasing locally, but there are some gaps that need to be addressed. Primarily, while there is significant quantitative and qualitative data surrounding motivations, perceptions, and actual purchase behaviour, there is little done to bridge the gap between each of these factors to determine consumer activity. Thus, further research based on this review should aim to develop an understanding of the interaction of these factors and the utility generated to the consumer. Quantitative data in this area of study will be beneficial to the current body of work by providing a detailed 
understanding of the decision making process of consumers when it comes to local food. This will provide a resource for marketers, policy makers, and researchers for drafting initiatives supporting local food producers. It will also help to build the body of knowledge surrounding this field, and support a framework for what is currently a new, uncertain field for agricultural business and policy. In addition, this research will provide an understanding of how traditional decision making and choice models apply to different product categories in which intangible factors are more of a focus than tangible, such as price.

Another area where further research will prove useful is in assessing the replicability of others' methodology and research. While there is data and findings available on Indiana [4], Nebraska [9], New England [8], and the United Kingdom [2], the perceptions of local food are steeped in the local culture and product availability. This research will provide an analysis of the use of this methodology in other geographical regions. It will also provide insight into the general applicability of these research methods, and provide results specific to the area of study. This insight will support further study of the local food culture in this area, and will indicate what special characteristics apply and make it unique.

\section{Limitations and Potential Issues}

As stated previously, a major difficulty common to research in this product category is the lack of concrete definitions of what a local product is. There are two possible approaches to address this limitation. The first is to leave this definition up to the judgement of the survey sample, and catalogue their definitions in the aim of seeing how that factor interacts with other definitions. The other method is to define locality, which mitigates the variable impact.

Additionally, it is important to note that it may be difficult to obtain a large sample size. Due to the more recent popularity of farmer's markets (a major source of local purchasing), the concept of buying local may be too new in consumers' minds for them to be able to articulate adequately to obtain the information needed. To address this, special attention will have to be paid to the design of the methodology to ensure clarity to the survey subjects.

The final major potential issue that may occur with this research is the potential to generalize results. Due to different growing seasons, products, and availability, results and findings may be limited to the location studied. Consumers in different regions will vary in their behaviour considerably, and this will need to be acknowledged by researchers who use other studies to examine the local food culture of their own area. However, future studies may provide insight into the ability to generalize findings using this methodology, and indicate what may need to be adapted to different cultural and geographical characteristics in future studies.

\section{ACKNOWLEDGEMENTS}

The researchers would like to acknowledge the College of Management and Economics for their support and funding of this research. Additionally, we would like to thank the interview subjects for their expertise and participation. This support provided a great deal of guidance, and we greatly appreciate the time and effort given to provide it.

\section{REFERENCES}

1. Schneider, M. and Francis, C. (2005). Marketing locally produced foods: Consumer and farmer opinions in Washington County, Nebraska. Renewable Agriculture and Food Systems, 20(4), 252-260.

2. Zepeda, L. (2009). Which little piggy goes to market? Characteristics of US farmers' market shoppers. International Journal of Consumer Studies, 33, 250-257.

3. Brown, C. and Miller, S. (2008). The impacts of local markets: a review of research on farmers markets and community supported agriculture (CSA).American Journal of Agricultural Economics, 90(5), 1296-1302. Conner, D., Montri, A., Montri, D., and Hamm, M. (2009). Consumer demand for local produce at extended season farmers' markets: guiding farmer marketing strategies. Renewable Agriculture and Food Systems, 24(4), 251-259.

4. Nørgaard, M., Bruns, K., Christansen, P. and Mikkelsen, M. (2007). Children's influence on and participation in the family decision process during food buying. Young Consumers, 8(3), 197-216.

5. Zepeda, L. and Jingam, L. (2006). Who Buys Local Food?. Journal of Food Distribution Research, 37 (3), 111.

6. Weatherell C., Tregear, A., and Johanne A. (2003). In search of the concerned consumer: UK public perceptions of food, farming, and buying local. Journal of Rural Studies, 19, 233-244.

7. Feagan, R. and Morris, D. (2009). Consumer quest for embeddedness: a case study of the Brantford Farmers' Market. International Journal of Consumer Studies, 33, 235-243.

8. Berlin, L., Lockeretz, W., and Bell, R. (2009). Purchasing foods produced on organic, small, and local farms: A mixed method analysis of New England consumers. Renewable Agriculture and Food Systems, 24(4), 267-275.

9. Thilmany, D., Bond, C. and Bond, J. (2008). Going local: exploring consumer behaviour and motivations for direct food purchases. American Journal of Agricultural Economics, 90(5), 1303-1309.

10. Hu, W., Adamowicz, W., and Veeman, M. (2006). Labeling context and reference point effects in models of food attribute demand. American Journal of Agricultural Economics, 88(4), 1034-1049. 
11. Jekanowski, M., Williams, D., and Schiek, W. (2000). Consumers' willingness to purchase locally produced agricultural products: An Analysis of an Indiana Survey. Agricultural and Resource Economics Review, 29 (8), 43-53.

12. Darby, K., Batte, M., Ernst, S. and Roe, B. (2008). Decomposing Local: A Conjoint Analysis of Locally Produced Foods. American Journal of Agricultural Economics, 90(2), 476-486.

13. Toler, S., Briggeman, B., Lusk, J. and Adams, D. (2009). Fairness, farmers markets, and local production . American Journal of Agricultural Economics, 91(5), $1272-1278$
14. La Trobe, H. (2001). Farmers' markets: consuming local rural produce. International Journal of Consumer Studies, 25(3), 181-192.

15. Toler, S., Briggeman, B., Lusk, J. and Adams, D. (2009). Fairness, farmers markets, and local production . American Journal of Agricultural Economics, 91(5), 1272-1278.

16. Wilson, G. and Wood, K. (2004). The influence of children on parental purchases during supermarket shopping. International Journal of Consumer Studies, 28(4), 329-336. 